\title{
Clinical and Endocrine Response to Repeated Daily Administration of Endotoxin in Pigs
}

Endotoxins of Gram-negative bacteria elicit biphasic fever, leukopenia, increased hypocalcemia, $\mathrm{PGF}_{2 \alpha}$ release, and blood-circulation shock in the mammalian body (Fredriksson 1984). The toxicity of a given endotoxin decreases after repeated endotoxin administration. This tolerance appears to arise through both non-immunological regulatory and immunological pathways. This first phase of tolerance exhibits no inter-endotoxin specificity, and appears to be caused by the lipid A portion of the endotoxin molecule. The later phase of tolerance, however, is endotoxin specific and is probably in part evoked by an immunological tolerance to the O-antigen polysaccharide chain of the endotoxin (Lindberg et al. 1983). The purpose of this project was to investigate the clinical and endocrine response to repeated daily administration of endotoxin in pigs.

Clinical signs (i.e anorexia, depression, ease and rate of breathing, and muscle tremors), temperature, leukocyte response, and $\mathrm{PGF}_{2 \alpha}$ metabolite levels were chosen as parameters to measure the degree of response (Fredriksson 1984). The procedure was as follows: 4 castrated male pigs were injected i.v. through a jugular catheter with $1 \mu \mathrm{g} / \mathrm{kg}$ body weight of Salmonella typhimurium endotoxin daily for 5 days. Blood was collected and clinical observations were made every 2 $\mathrm{h}$ according to the following schedule: $-2,0$, 2, 4, 6 and $8 \mathrm{~h}$. Catheters were kept open by injection of heparinized saline (Cort et. al. 1986).

The averaged results of the 4 pigs can be seen in Fig. 1. Clinical results are depicted in Table 1.

Prostaglandin $F_{2 a}$ release, measured by radioimmunoassay (RIA) of 15-ketodihydro$\mathrm{PGF}_{2 \alpha}$ metabolite, showed a sharp rise within the first $2 \mathrm{~h}$. This rise declined slowly to the original value after $8 \mathrm{~h}$, giving a total area under the curve of $1917 \mathrm{~mm}^{2}$. Two

Table 1. Clinical symptoms after repeated daily endotoxin administration.

\begin{tabular}{lccccc}
\hline Day & Pig \# 1 & Pig \# 2 & Pig \# 3 & Pig \# 4 & $\begin{array}{c}\text { Subjective } \\
\text { total score }\end{array}$ \\
\hline 1 & +++ & +++ & +++ & +++ & 12 \\
2 & ++- & +++ & ++- & --- & 7 \\
3 & --- & +-+ & ++- & -+- & 5 \\
4 & --- & +++ & --- & --- & 3 \\
5 & --- & --- & --- & --- & 0 \\
\hline
\end{tabular}

Key $+++=$ anorexia, depression, muscle tremors and/or raspy breathing.

$---=$ no anorexia, no depression, no muscle tremors or breathing difficulty. 

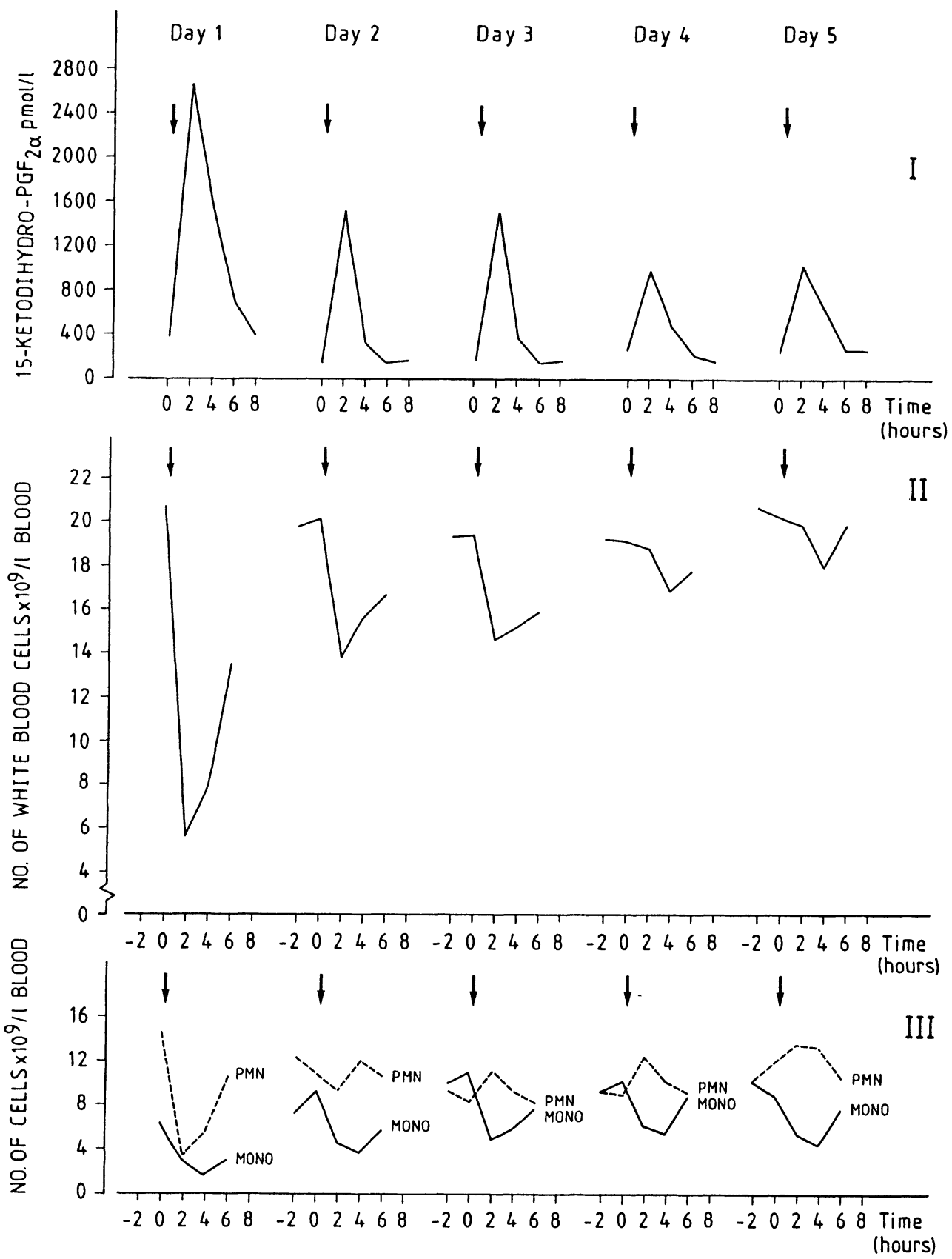

Figure 1. Peripheral plasma levels of 15 -ketodihydro-PGF ${ }_{2 \alpha}$ (panel I), total number of white blood cells (panel II), and differential counts (panel III) in four pigs treated daily for five days with Salmonella typhimurium endotoxin (time of injection denoted by arrows). 
hours after endotoxin administration on the second through fifth days this rise was lower; the areas under the curves were $41 \%, 41 \%$, $27 \%$, and $34 \%$ of the area under the curve on day 1 . Note that although absolute release of $\mathrm{PGF}_{2 \alpha}$ decreased after the first day of injection, a peak of $\mathrm{PGF}_{2 \alpha}$ release occurred after each endotoxin treatment. This $\mathrm{PGF}_{2 \alpha}$ peak was evident even after the clinical response to endotoxin had disappeared.

The pyrogenicity of endotoxin is unquestionable. In this experiment, however, accurate measurement of body temperature was difficult and the response after endotoxin varied considerably. Therefore, this parameter was not included in the analysis of response.

Leukocyte response changed between days 1-5. On day 1 , time $2 \mathrm{~h}$, polymorphonuclear cells (PMN) and mononuclear cells (M) decreased in number; although the decrease in $\mathrm{PMN}$ was quicker, $\mathrm{M}$ numbers continued to decrease over 4 h. Day 2 also showed a decrease in PMN numbers after endotoxin administration. On day 3-5, however, the numbers of PMN actually increased after endotoxin injection. This increase was largest on day 5. Mononuclear cell response did not vary as did that of PMN; the pattern after endotoxin administration was the same each day. Note that if the total leukocyte count is examined instead of PMN/M count, the response to endotoxin appears only to decrease day by day, i. e. some form of tolerance occurs. This tolerance may be due to both humoral and cell-mediated immune responses (Lindberg et al. 1983).

Endotoxin may work in part through a stimulation of pleuripotent cells in the bone marrow (Madonna et al. 1986). On day 1, the average number of immature neutrophils rose from 0 to $26 \times 10^{9}$ cells/liter blood (time -2 vs. time 6 h). On day 5 , average immature neutrophil numbers increased from 0 to $11 \times 10^{9}$ cells/liter blood at $4 \mathrm{~h}$, and decreased again to less than $1 \times 10^{9}$ cells $/$ liter blood by $6 \mathrm{~h}$. This may also indicate that whereas endotoxin induced leukopenia was so severe on the first day that the bone marrow was stimulated to release immature neutrophils, later administration could not cause this response. Hopefully, further investigations will be able to explain the mechanism of tolerance induction by repeated endotoxin administration.

\section{Chahna Yagoda and Ann-Christin \\ Bylund-Fellenius,}

Pharmacia LEO Therapeutics AB, Uppsala, Sweden.

\section{Hans Kindahl,}

Swedish University of Agricultural Sciences, Department of Obstetrics and Gynaecology, Uppsala, Sweden.

\section{References}

Cort $N$, Kindahl H, Einarsson S: The effect of a Gram-negative bacterial endotoxin and cloprostenol on the plasma levels of 15-keto-13,14dihydro-PGF $2 \alpha$, progesterone, oestradiol-17 $\beta$, oestrone sulfate and lutenizing hormone in non-pregnant and 60 days pregnant gilts. Anim. Reprod. Sci. 1986, 10, 147-162.

Fredriksson G: Some reproductive and clinical aspects of endotoxins in cows with special emphasis on the role of prostaglandins. Acta vet. scand. 1984, 25, 365-377.

Lindberg A, Greisman S, Svensson $S$ : Induction of endotoxin tolerance with non-pyrogenic $\mathrm{O}$-antigenic oligosaccharide - protein conjugates. Infect. Immun. 1983, 40, 888-895.

Madonna GS, Peterson JE, Ribi EE, Vogel SN: Early-phase endotoxin tolerance: Induction by a detoxified lipid A derivative, monophosphoryl lipid A. Infect. Immun. 1986, 52, 6-11.

(Received August 5, 1988).

Reprints may be requested from: Hans Kindahl, Department of Obstetrics and Gynaecology, Swedish University of Agricultural Sciences, S-750 07 Uppsala, Sweden. 
